\title{
Development of a PoE Switch Based Remote Control System for Controlling Home and Office Appliances with Data Communication Facility
}

\author{
Mohammad Shah Alamgir ${ }^{1}$, A. Zahed Chowdhury ${ }^{2}$ and KaziTanvir Ahmmed ${ }^{3}$ \\ Dept. of Applied Physics, Electronics and Communication Engineering, \\ University of Chittagong \\ Chittagong-4331, Bangladesh \\ shah_a@cu.ac.bd,shah_a3514@yahoo.com
}

\begin{abstract}
The main objective of this work is to design and construct a PoE switch based system: to control electric appliances such as light, fan, heater, washing machine, motor, TV, etc. and simultaneously data communication facility. Especially PoE switch can manage power and data separately by a splitter which motivated the need to research into it not only for industrial application but also for domestic use or home use. Power is use for controlling devices and data is for communication purpose. This system will play an important role for the elderly and physically disabled people to control their home appliances in intuitive and flexible way through Wi-Fi and internet. This system is password protected so only authorized person can control any sensitive electrical appliances. Most commercially available home automation systems are used only for control purpose. But by our proposed PoE based system we can control electrical appliances as well as data communication by the same switch port.
\end{abstract}

Keywords: Home appliance, Power over Ethernet (PoE) switch, Power over Ethernet (PoE) Splitter, Internet, Wi-Fi

\section{Introduction}

Home automation system focuses more on comfort that can control elements of home environment such as lights, fans, air conditioners, television sets, electronic doors, security cameras, audio/visual equipment, computer systems etc.

Power over Ethernet (PoE) switch offers the performance and ease of use to get the business connected quickly and easily. We can use this switch to connect network devices - including computers, printers, and servers - to share and transfer files and videos across our network. Power over Ethernet (PoE) easily and cost-effectively powers IP telephones, wireless access points, and video cameras. In this paper we are trying to show something different that is we can use this switch also for controlling home/ office appliances.

There are many benefits to use this, compared to conventional systems. Our proposed system is to develop a cost effective \& password protected solution that will provide controlling of home appliances remotely in the absence of homeowner as well as data communication facility. Though devices connected as home and office appliances consume electrical power. These devices should be controlled as well as turn on /off if required. Most of the time it was done manually. Now it is a necessity to control devices more effectively and efficiently at anytime from anywhere. This system is designed for controlling arbitrary devices by use Wi-Fi and internet network and also provides data communication facilities. There are many different types of home automation systems available. These systems are typically designed and purchased for different purposes. In 
fact, one of the major problems of these systems is that these are neither interoperable nor interconnected. For the most commercially available home automation systems, these appliances usually have to be specially designed to be compatible with each other and with the control unit. Most commercially available home automation systems are all-inone solutions which require that all controllable appliances are from the same company, or must be approved as compatible with said company's system [1]. Moreover these systems normally come with a proprietary, dedicated device which acts as the control centre. These complex systems usually need to be integrated when the building is constructed and must be planned in advance. They are also difficult to upgrade or replace once installed. The overall investment adds up considerably and is financially infeasible in most cases [2]. These drawbacks hinder the popularity of such systems. There are some home automation systems has been implemented, some of which use internet to control home appliances [3-4], some use mobile phones [5-7], some use parallel ports [8], but all of these are costly and hard to implement and design only for control purpose. The objective of the proposed system is to offer a low-cost solution for a home automation system that overcomes the above drawbacks and internet services or data sharing is the added advantage. The system use PoEswitch and splitter which splits data and power of the PoE switch. Data is for internet use and power is for control the home appliances. A PoE switch can be different port based such as 8 ports, 16 ports, 24 ports, 48 ports. So we can make a control system which can control the number of appliances depend on the switch port.

\section{Proposed Method}

The design demonstrates a system that allows one to control home appliances from anywhere outside/inside of the home through internet/Wi-Fi. The power supply for each appliance is wired through an electromechanical relay. A number of relays are used depending on the number of appliances to be controlled. All the relays are controlled by $+5 \mathrm{v}$ power from $\mathrm{PoE}$ switch port with the help of PoE splitter which splits a networked PoE signal into separate power and Gigabit data sources. Homeowner from anywhere outside home using internet and inside house building from anywhere can access PoE switch through Wi-Fi by appropriate password. Home appliances can be on/off by switching relay on/off when enable/disable the power of PoE switch but data communication will not disturb from the same port. In Figure $1 \mathrm{We}$ show the block diagram of our proposed system and Figure 2 and Figure 3 shows the flowchart.

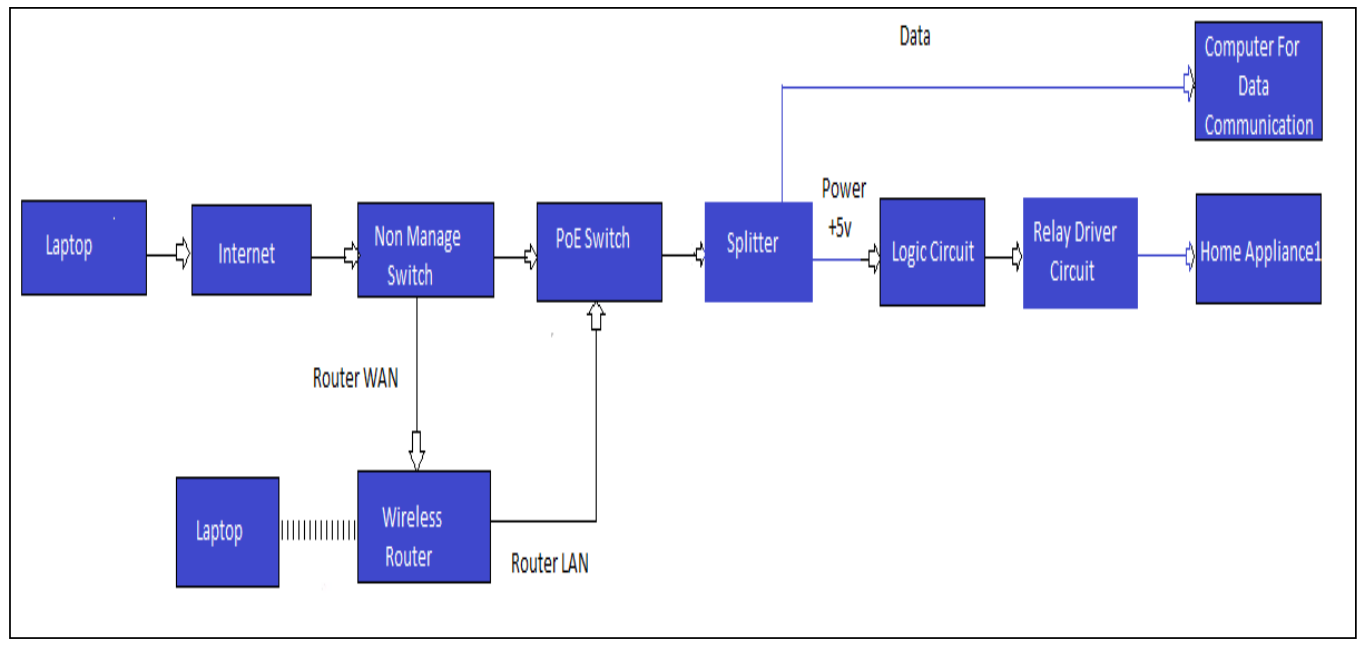

Figure 1. Block Diagram of our Designed System 
Initially, an authentic person can directly login PoE switch through internet/Wi-Fi because PoE switch's static IP is public IP. From Figure 2 we see that after successfully login PoE switch we can see PoE port configuration option, so we can manage power. When ENABLE the power of the port then turn ON the desired device because it sends logic $1(3.5-5 \mathrm{~V})$ to the Logic circuit through the PoE splitter. Then the logic circuit sends a 1 to the transistor. It will activate the transistor used to energize the relay. Inside a relay, there is an inductor (a wire coil), when energized with an electric pulse, will generate a magnetic field. The second part of a relay is a system of metallic arms, which make up the physical contact of the switch. When the relay is on, or an electric pulse is sent to the relay, the swing or switching arm of the relay moves to another contact of the relay (The relay we used has two contacts). The arm moves as the generated magnetic field pulls the swinging arm toward the inductor (or wire coil). And hence the AC circuit is completed and the electrical appliance is turned ON. When the DISABLE the power of the switch port then it sends logic $0(0-1.5 \mathrm{~V})$ to the logic circuit through the splitter then the logic circuit sends a 0 to the transistor. It will deactivate the transistor used to energize the relay. So the arm of the relay is swing back to another position, which makes the path of the current flow open. And hence electrical appliance is turned OFF. The terminal input of each appliances is wired across the Common and Normally Open terminals of the relays, thus the power to the appliances is switched ON or OFF depending on whether the relay is active or not. From Figure 3 we see that we can control data transfer by going port configuration option. So data transfer and power control is completely managed separately by two separate configuration option.

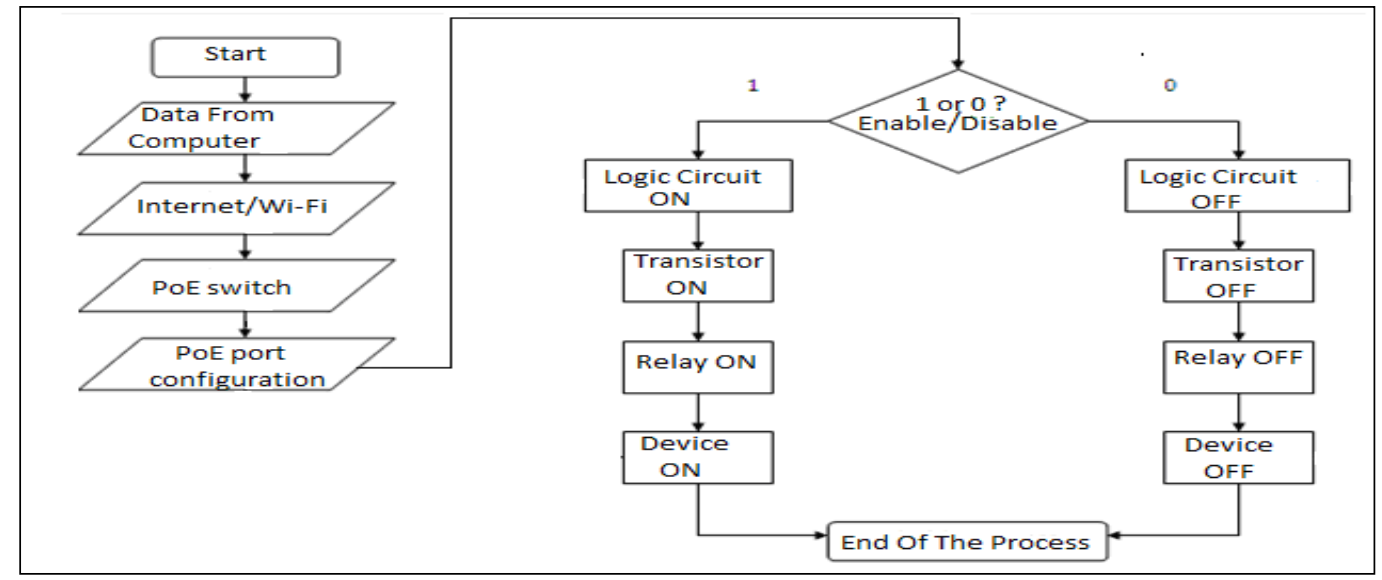

Figure 2. The Flow Chart of the Device Control

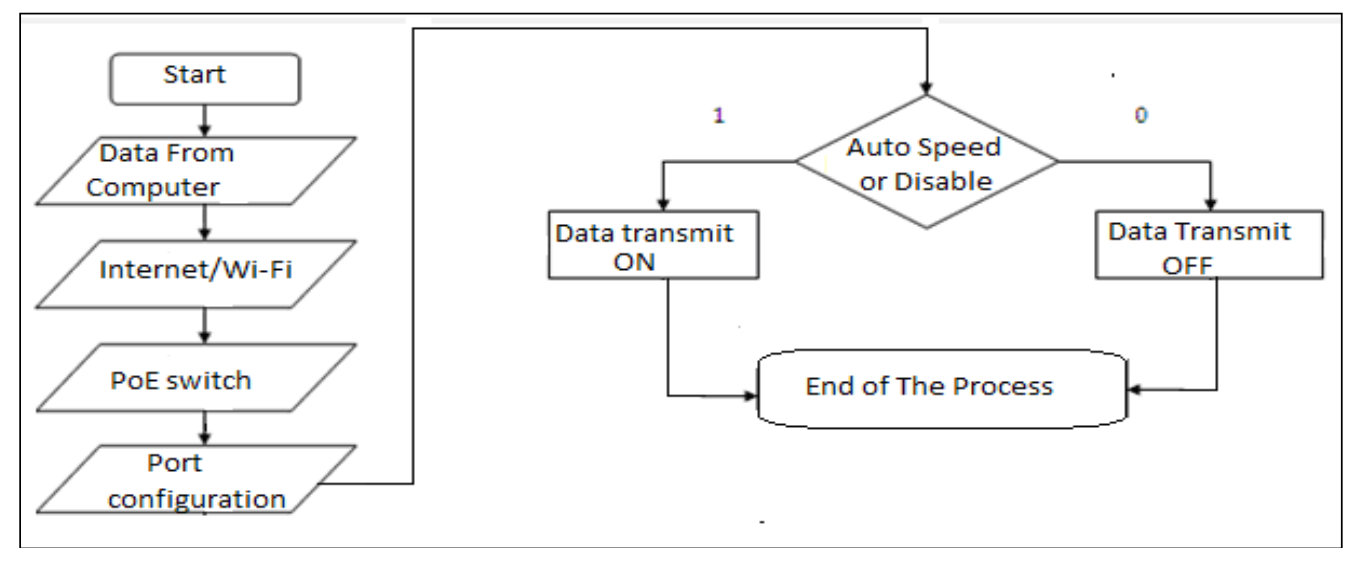

Figure 3. The Flow Chart of the Data Transmission 


\section{Hardware Implementation}

There are different brands of PoE switch; in this project we used TPE-80WS model PoE manageable switch and the Gigabit Power over Ethernet Splitter (TPE-112GS).

\subsection{8-Port Gigabit Web Smart PoE Switch[9]}

The 8-Port 10/100/1000Mbps Web Smart PoE Switch offers advance switching controls and provide power to network devices using Ethernet cables. This scalable and cost effective solution allows a managed network to efficiently expand to previously unattainable levels.

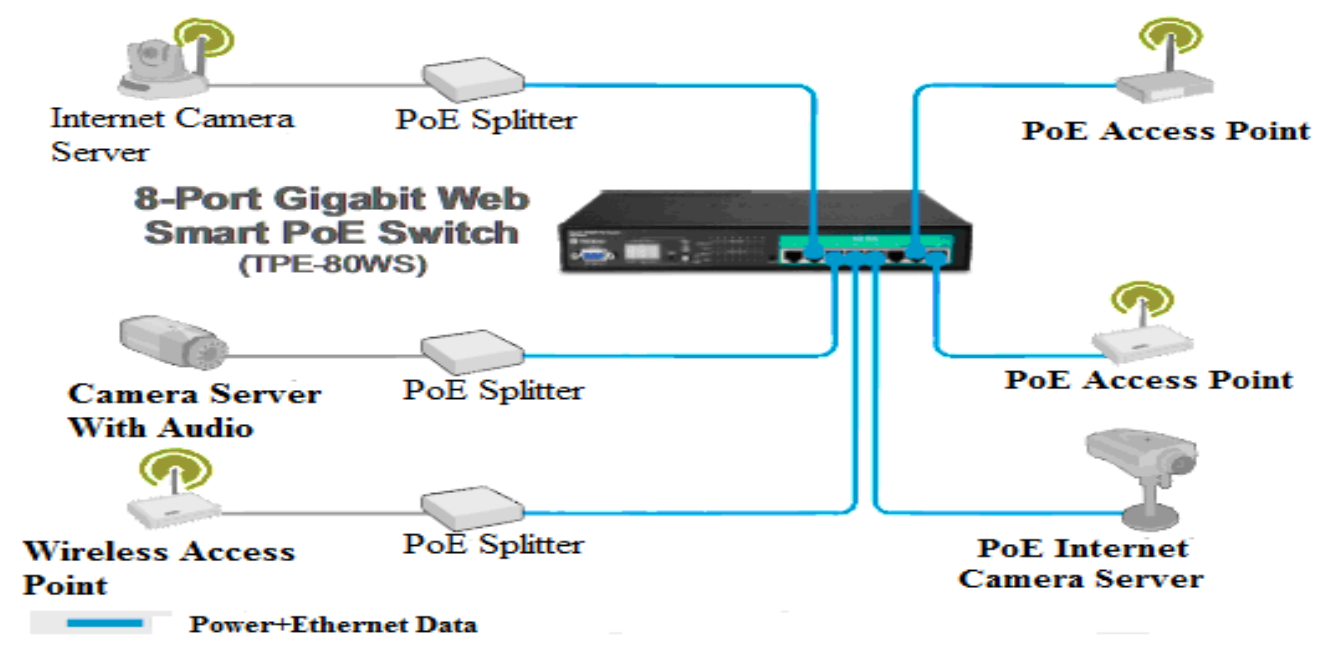

Figure 4. 8-Port Gigabit Web Smart PoE Switch

The feature rich 8-port switch offers advanced network management, Link Aggregation, VLAN, trunking and QoS technology to meet the accelerating demand for secure manageable networks. LED displays show device status for easy power management and troubleshooting. PoE technology conveniently eliminates the need to install networked devices, such as TRENDnet IP cameras and access points, near a power outlet, thereby reducing equipment and installation costs. PoE switch has its Graphical user interface. After login by authentic password we can manage power and data separately of all the switch ports from configuration option are shown in Figure 5, Figure 6 and Figure 7.

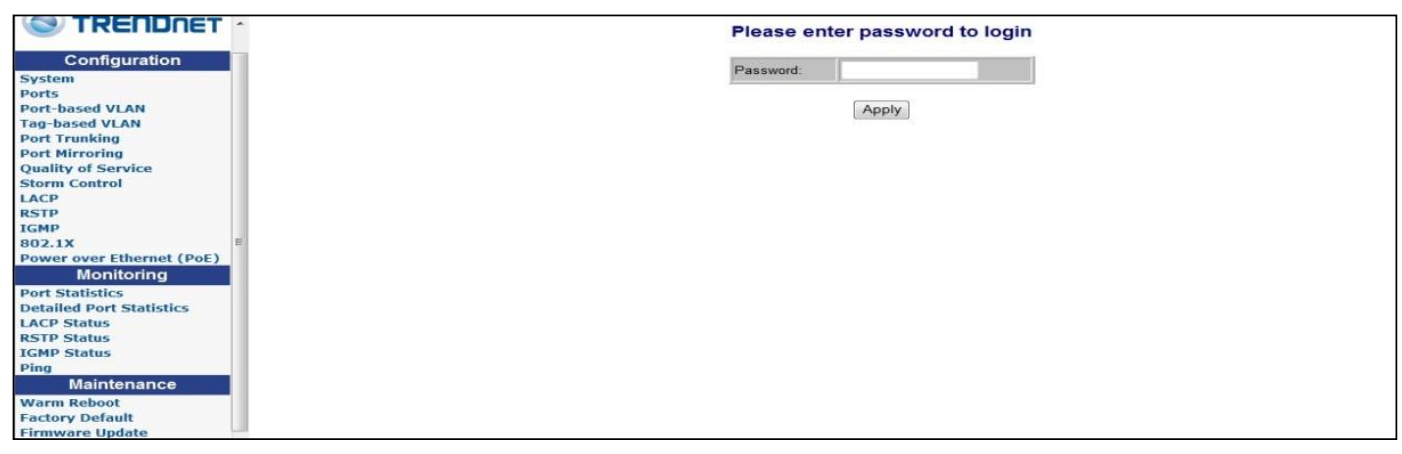

Figure 5. Software Interface of Trendnet PoE Switch 


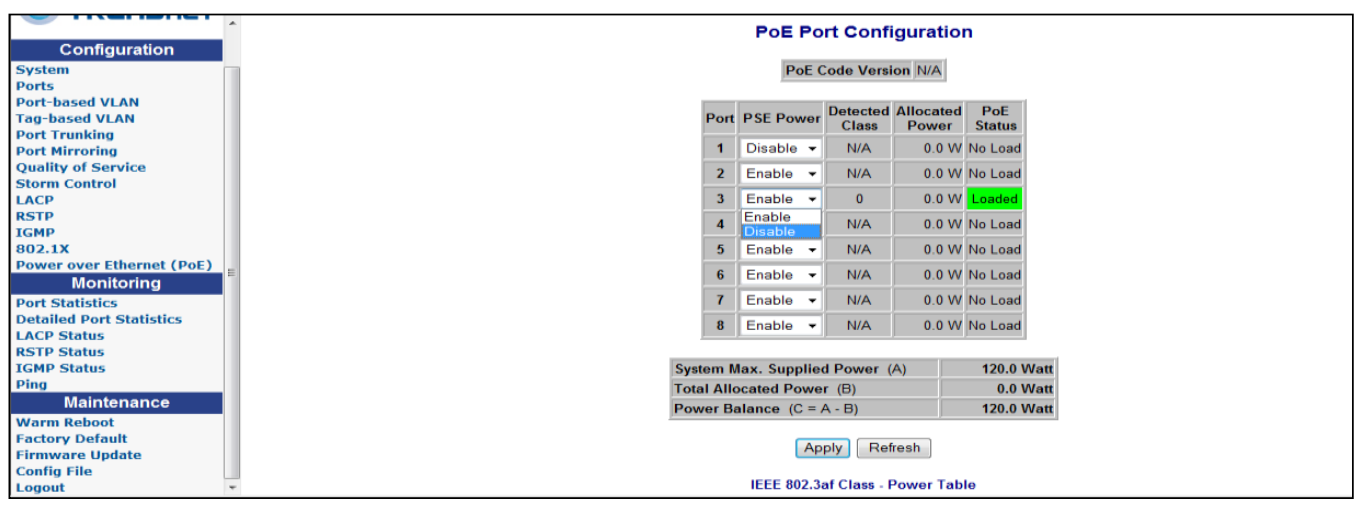

Figure 6. Software Interface of PoE Port Configuration

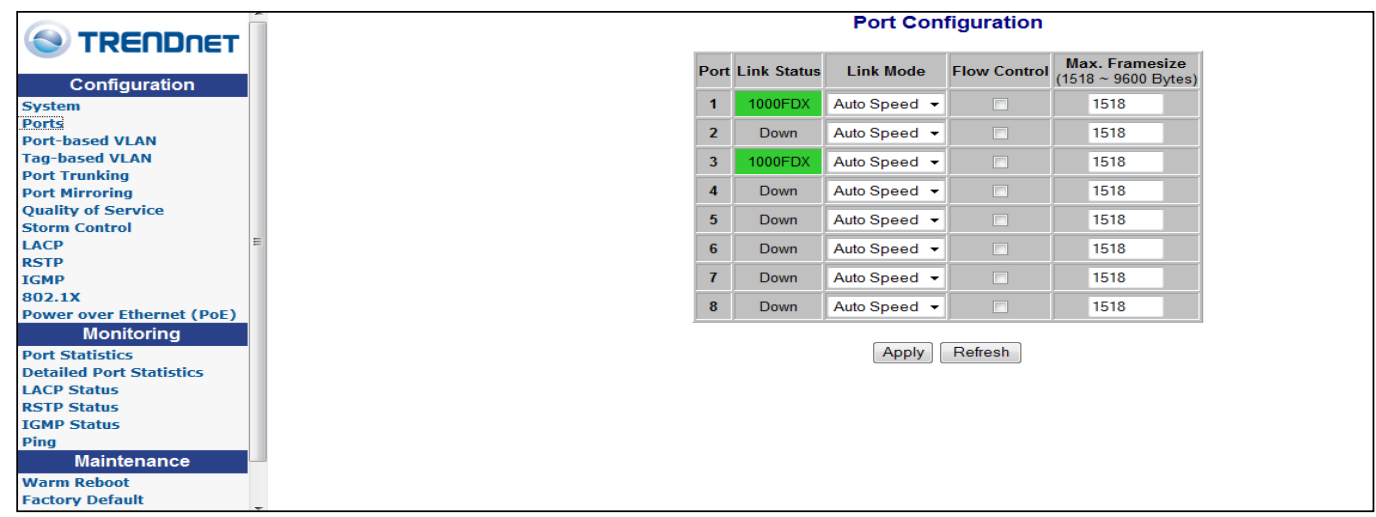

Figure 7. Software Interface of Port Configuration

\subsection{Gigabit Power Over Ethernet (PoE) Splitter[10]}

The Gigabit Power over Ethernet Splitter (TPE-112GS) splits a networked PoE signal into separate power and Gigabit data sources. This device allows administrators to run Gigabit speed PoE cables over long distances and then split the PoE signal into separate data and power sources in order to network non-PoE devices. Save installation and equipment cost when installing access points, IP cameras and more in remote locations. No need to install network devices near a power outlet.

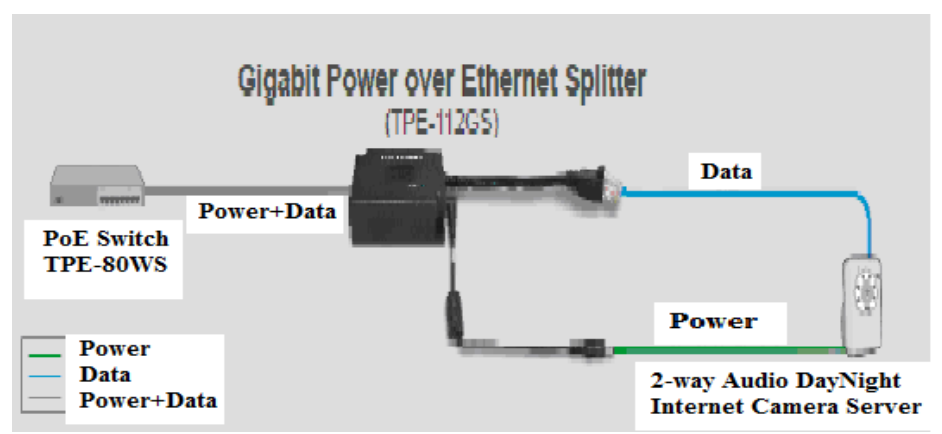

Figure 8. Gigabit Power over Ethernet (PoE) Splitter

This compact device safeguards valuable network equipment with short circuit protection. Quickly create an integrated PoE and non-PoE network at Gigabit speeds. 


\subsection{Wireless Router[11]}

In this research we used Linksys wrt320 model wireless router. Wireless networks are convenient and easy to install, so homes with high-speed Internet access are adopting them at a rapid pace. Because wireless networking operates by sending information over radio waves, it can be more vulnerable to intruders than a traditional wired network.

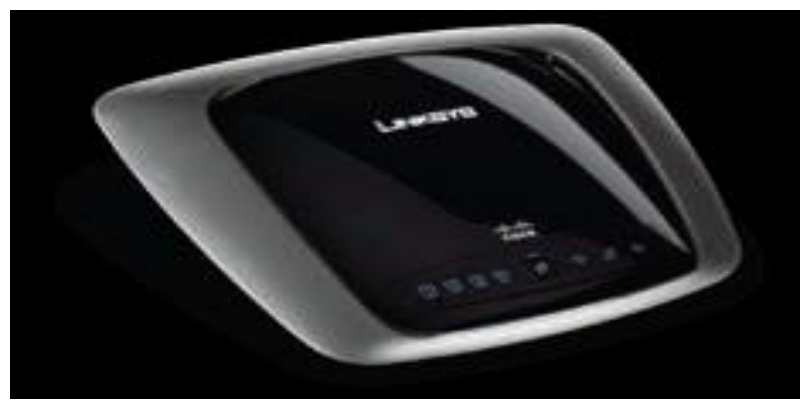

Figure 9. Linksys wrt320 Model Wireless Route

\section{System Implementation}

From Figure 10 we see that a link from ISP is connected to the nonmanageable switch. From this switch one link is connect to wireless router and another link is connect to the PoE switch. We setup public IP provided by ISP in the static IP field of PoE switch and in the WAN interface of wireless router. Inside home any one can setup by automatically or manually of their laptop, desktop, mobile phone and network devices by private IP under 192.168.1.0/24 network.

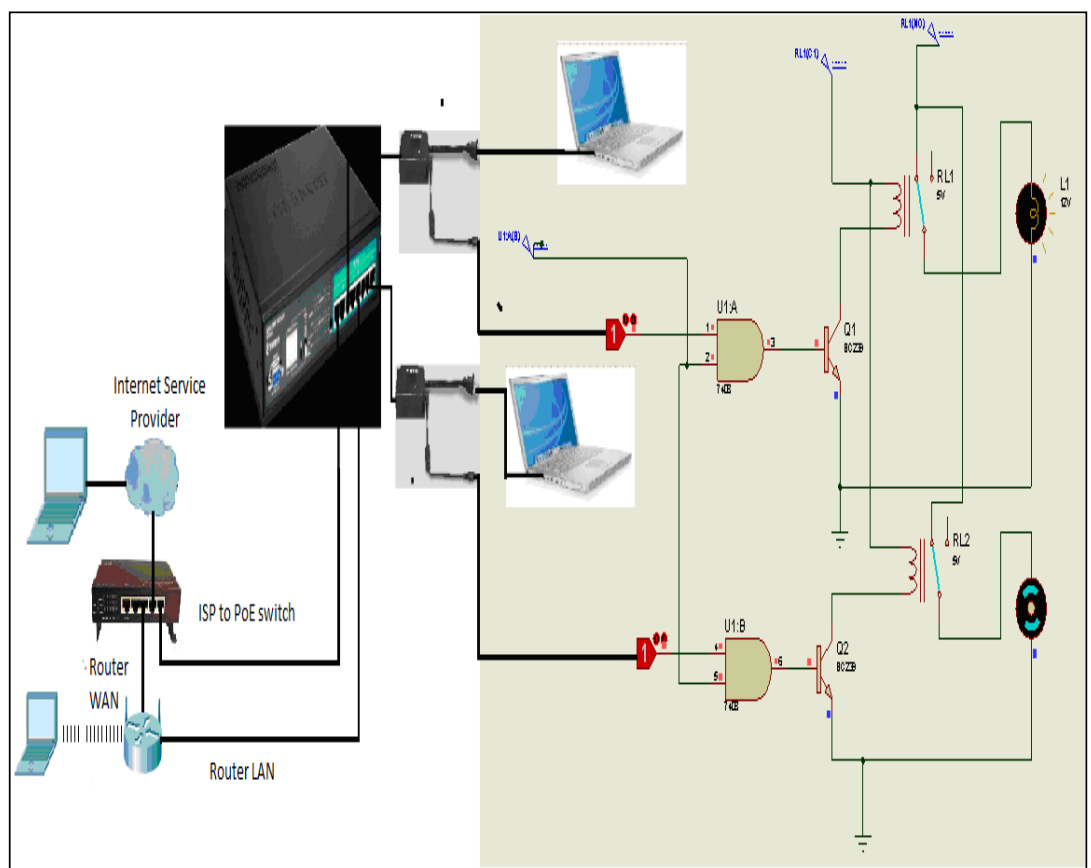

Figure 10. Computer Control System for Home Appliances: Circuit Diagram

If need authentic person can login the PoE switch by typing public IP of the switch in their browser address field. There are many configuration options in this switch. We can ENABLE/DISABLE of PSE power from PoE port configuration option. We can also observe PoE status and allocated power of a load by PoE configuration option. We can also manage data transmission by port configuration. Splitter send $+5 \mathrm{v}$ to logic the circuit 
for controlling devices and data to the IP based device for data sharing purposes. In Figure (10) we show the circuit diagram of our designed system in simulation environment. However, Transistors and ICs must be protected from the brief high voltage produced when a relay coil is switched off.

As an experimental basis; we have connected one fan from port 3 shown in Figure 6. A splitter is connected with switch port 3 through a Straight through cable. Data and power is split by splitter. Data cable is connected to IP based device for communication purpose under Wi-Fi range and power cable is connected to logic circuit for control the relay. If the connection is successful then we are able to control the appliances from the computer which is connected to switch by wirelessly. Each device can be controlled either as an ON or OFF mode by pressing Enable or Disable of power from switch port shown in Figure 11 and figure 12.

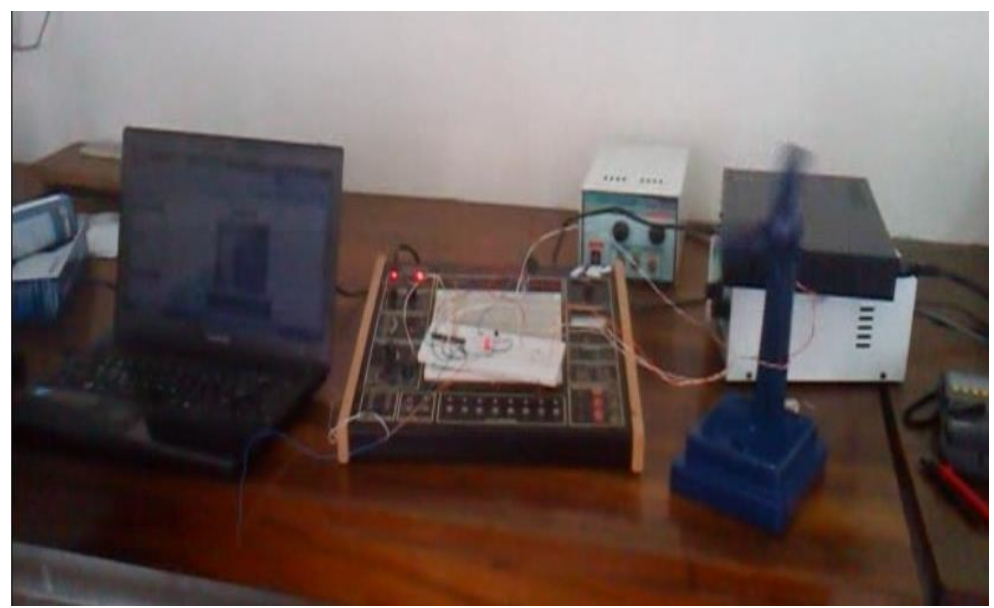

Figure 11. Practical Circuit Diagram when Appliance is ON Mode

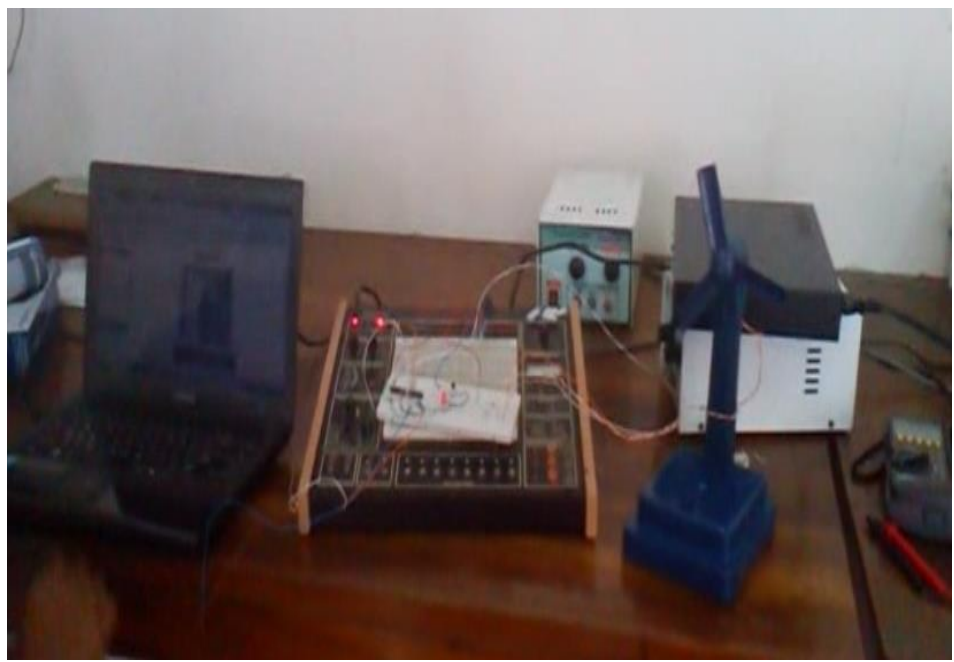

Figure 12. Practical Circuit Diagram when Appliance is OFF Mode

\section{Performance Test}

When people outside from home or office need to on or off a remote electric device, he just needs to login the PoE switch using internet or Wi-Fi. After that he just enables or disables the power of the particular switch port from which the target device is connected. By enable or disable the power of the switch port, internet service or data transfer will not 
disturb from the same port because power and data management option of this switch is separate.

We can explain performance result by the following table:

Table 1. Performance Result

\begin{tabular}{|c|c|c|c|c|c|}
\hline \multirow[t]{2}{*}{ Port } & \multirow[t]{2}{*}{ Devices } & $\begin{array}{c}\text { PoE Port Configuration } \\
\text { Enable }\end{array}$ & $\begin{array}{c}\text { PoE Port } \\
\text { Configuration } \\
\text { Disable }\end{array}$ & $\begin{array}{l}\text { Port configuration } \\
\text { Auto Speed }\end{array}$ & $\begin{array}{c}\text { port configuration } \\
\text { Disable }\end{array}$ \\
\hline & & Control Device & Control Device & Data Transmit & Data Transmit \\
\hline 1 & ISP Link & Device Not Connected & Device Not Connected & OK (ISP LINK) & OFF \\
\hline 2 & $\begin{array}{c}\text { Wireless Router } \\
\text { LAN }\end{array}$ & Device Not Connected & Device Not Connected & OK (Router LAN) & OFF \\
\hline 3 & $\begin{array}{c}\text { Splitter } \\
\text { Connected } \\
\end{array}$ & ON & OFF & OK & OFF \\
\hline 4 & $\begin{array}{c}\text { Splitter } \\
\text { Connected } \\
\end{array}$ & ON & OFF & OK & OFF \\
\hline 5 & $\begin{array}{c}\text { Splitter } \\
\text { Connected }\end{array}$ & ON & OFF & OK & OFF \\
\hline 6 & $\begin{array}{c}\text { Splitter } \\
\text { Connected }\end{array}$ & ON & OFF & OK & OFF \\
\hline 7 & $\begin{array}{c}\text { Splitter } \\
\text { Connected } \\
\end{array}$ & ON & OFF & OK & OFF \\
\hline 8 & $\begin{array}{c}\text { Splitter } \\
\text { Connected }\end{array}$ & ON & OFF & OK & OFF \\
\hline
\end{tabular}

\section{Conclusion}

The system for the "Home Automation Network" has a vast scope \& almost limitless application in today's technology driven market. Nowadays most office or home already owns the requisites such as a desktop PC or laptop, PoE switch, wireless router. Hence the Cost of our proposed system is considerably reduced. The basic vision of the system is to provide a convenient \& secure system to the user, which would aid the high degree of mobility, data communication and control appliances. By using PoE switch we develop a novel system to control home or office appliances besides its own performance.

\section{References}

[1] Home Automation Software, http://www.vagueware.com/top-10-home-automatio n-software-thatwillequip-your-adobe-for-the-21st-century.

[2] Home automation system, [Online] Available: http://voices.yahoo.com/the-best-homeautomation system- best-price6119570.html? cat=15.

[3] T. Kim, H. Lee and Y. Chung, "Advanced Universal Remote Controller for Home Automation and Security", IEEE Transactions on Consumer Electronics, vol. 56, no. 4, (2010), pp. 2537-2542.

[4] J. C. Nunes and J. C. M. Delgado, "An Internet application for home automation", Electro technical Conference, MELECON 10th Mediterranean, vol. 1, (2000), pp. 298 - 301.

[5] H. Sumino, N. Ishikawa, H. Tsutsui, H. Ochi, Y. Nakamura and Y. Uchida, "Home Appliance Control from Mobile Phones", Consumer Communications and Networking Conference, CCNC $4^{\text {th }}$ IEEE, (2007), pp. $793-797$.

[6] N. Dickey, D. Banks and S. Sukittanon, "Home Automation using Cloud Network and Mobile Devices", Proc. of IEEE International Conference at Southeast on, (2012), pp. 1-4.

[7] S. Sharma, G. Chitranshi, B. Mahato, A. K. Srivastava, N. Gupta and B. P. Singh, "Control of HomeAppliances through IR interface using web (GPRS) enabled Mobile Phones", International journal of advanced engineering sciences and technologies (IJAEST), vol. 6, no. 2, (2011), pp. $242-245$.

[8] X. Zhang, J. Sun and L. Zhou, "Development of an Internet Home Automation System using Java and Dynamic DNS Service", Sixth International Conference on Parallel and Distributed Computing, Applications and Technologies, PDCAT 2005, (2005), pp. 537 - 539.

[9] http://www.trendnet.com/langen/products/ proddetail.asp?prod=125_TPE-80WS.

[10] http://www.trendnet.com/langen/products/proddetail.asp?prod=130_TPE-112GS.

[11] http://www.cnet.com/products/linksys-dual-band-wireless-n-gigabit-router-wrt320n/. 